\title{
Postcranial axial skeletal pathology in Commerson's dolphins Cephalorhynchus c. commersonii from Tierra del Fuego, Argentina
}

\author{
Analía A. San Martín ${ }^{1,2, *}$, Natalia A. Dellabianca ${ }^{1,2}$, Eduardo J. Gimeno ${ }^{3}$, \\ Marie-Françoise Van Bressem ${ }^{4}$
}

\begin{abstract}
${ }^{1}$ Centro Austral de Investigaciones Científicas (CADIC), Bernardo Houssay 200, Ushuaia, 9410, Tierra del Fuego, Argentina
${ }^{2}$ Museo Acatushún de Aves y Mamíferos Marinos Australes (AMMA), Sarmiento 44, Ushuaia, 9410, Tierra del Fuego, Argentina

${ }^{3}$ Facultad de Ciencias Veterinarias, Universidad Nacional de La Plata, 60 y 118, 1900 La Plata, Argentina

${ }^{4}$ Cetacean Conservation Medicine Group (CMED), Peruvian Centre for Cetacean Research (CEPEC), Museo de Delfines, Lima 20, Peru
\end{abstract}

\begin{abstract}
Commerson's dolphins Cephalorhynchus c. commersonii are the small cetacean most frequently found stranded along the coast of Tierra del Fuego, Argentina, but little is known about their pathologies. We examined the postcranial axial skeleton of 425 Commerson's dolphins collected in the period 1974-2011 for the presence of pathologies. Miscellaneous lesions were detected in 107 (25.2\%) of the specimens. Among them, idiopathic hyperostosis was the most frequent pathology $(73.8 \%)$, followed by spondyloarthropathy $(40.2 \%)$. Traumata $(25.2 \%)$, spondylitis $(10.3 \%)$ and osteoarthritis $(11.2 \%)$ occurred less frequently. The type of lesion was statistically associated with the region of the vertebral column. Idiopathic hyperostosis occurred significantly more frequently in the lumbar vertebrae than in other parts of the vertebral column, while spondyloarthropathy was more frequent in the thoracic and caudal vertebrae. Both conditions were predominantly seen in mature dolphins. Osteoarthritis affected the transverse processes of the thoracic vertebrae of 6 males, 3 females and 3 individuals of undetermined sex, all mature. Healed and unhealed fractures were observed in the ribs of 27 specimens and in the transverse processes of 3 others. Spondylitis of various degrees of severity affected the cervical, thoracic, lumbar and caudal regions of 11 individuals. Together these data indicate that bone lesions and traumata commonly occur in Commerson's dolphins, likely causing pain and morbidity in severe cases.
\end{abstract}

KEY WORDS: Skeletal pathology - Idiopathic hyperostosis - Spondylitis · Osteoarthritis · Degenerative lesions $\cdot$ Traumata $\cdot$ Osteolysis $\cdot$ Commerson's dolphins $\cdot$ Cetacean

Resale or republication not permitted without written consent of the publisher

\section{INTRODUCTION}

Vertebral lesions in cetaceans affect individuals from all age classes, causing severe functional limitations or even death (Kompanje 1999, Sweeny et al. 2005, Félix et al. 2007). Some are the result of degenerative processes associated with aging, while others are caused by trauma, mechanical stress, inflammatory processes and pathogens. Degenerative lesions include osteoarthritis, 'idiopathic hyperostosis' and spondyloarthropathy among others. Osteoarthritis is a disorder of the synovial joints that may be caused by repeated and excessive mechanical stress and traumata (Salter 2002). It is characterized by a degeneration of the articular cartilage, leading to fissures and loss of the joint surface, and may be accompanied by osteophytes formation and thickening of the subchondral bone plate (Martel-Pelletier 2004). 
Spondyloarthropathy refers to any joint diseases of the vertebral column and includes ankylosing spondylitis (Kompanje 1999). Spondyloarthropathy often results from the degeneration of the intervertebral discs and mostly occurs in adult animals (Kompanje 1995a, Galatius et al. 2009). Idiopathic hyperostosis of the vertebrae is characterized by excessive growth or thickening of the bone tissue that does not affect the cartilage and intervertebral discs and occurs in the absence of subchondral bone remodeling (Lagier 1989). It takes place mainly in the area of tendon and ligaments insertion, i.e. areas of strong muscle tension (de Smet 1977). Traumata, such as fractures, may be the result of intra- or inter-specific interactions or may be caused by anthropogenic factors, such as entanglement and ship strikes (Oremland et al. 2010, Groch et al. 2012). Spondylitis is an acute or chronic infection of the vertebrae characterized by bone destruction and new bone formation that may occur between several vertebrae and affect (spondylodiscitis) or not (spondylitis) the intervertebral disc (Kompanje 1995a,b, Groch et al. 2012). Other conditions include soft tissue ossification and intraspongious disc herniation (La Sala et al. 2012, Nganvongpanit et al. 2017). Though these bone lesions and traumata have been documented in cetaceans from several ocean provinces (Kompanje 1995a, 1996, 1999, Kompanje \& García Hartmann 2001, Van Bressem et al. 2006, 2007, Laeta et al. 2010, Oremland et al. 2010, Groch et al. 2012, Bertulli et al. 2015, San Martín et al. 2016), they have never been reported in the Commerson's dolphin Cephalorhynchus c. commersonii.

The Commerson's dolphin, including the subspecies Cephalorhynchus c. commersonii and C. c. kerguelenensis, is one of the most common small cetaceans inhabiting the coastal waters of the Southwest Atlantic Ocean and is the species most frequently bycaught in artisanal coastal gill nets in the provinces of Santa Cruz and Tierra del Fuego, Argentina (Goodall \& Schiavini 1994, Iñíguez et al. 2003). It is small and stout, with adults growing to $\sim 145 \mathrm{~cm}$. Sexes are easily distinguished by the form of the genital black patch. Shaped like a teardrop in males, this patch completely covers the genital slit. In females, the patch has 2 lateral lobed projections and only partially covers the genital slit (Goodall et al. 1988, Robineau et al. 2007). The total number of vertebrae in Cephalorhynchus c. commersonii varies between 63 and 66, including 7 cervical, 12 to 14 thoracic, 13 to 15 lumbar and 26 to 32 caudal vertebrae. There are 11-13 pairs of true ribs, 1 pair of floating ribs and 7 pairs of sternal ribs (Goodall et al. 1988).
Initiated in the 1970s by Dr. Goodall in Tierra del Fuego, the R. Natalie P. Goodall (RNP) program has been collecting stranded or incidentally caught cetaceans and pinnipeds for $>50 \mathrm{yr}$. Currently the RNP marine mammal's collection has the world's largest number of Commerson's dolphin skeletal remains. To provide insight into the diseases affecting this species, we examined the postcranial axial skeleton of 425 individuals stranded along the coast of Tierra del Fuego between 1974 and 2011 for the presence of lesions and traumata and evaluated their correlation with sex, age and vertebral regions.

\section{MATERIALS AND METHODS}

\subsection{Specimens}

We studied the postcranial axial skeletal pathologies of 425 Cephalorhynchus c. commersonii from the RNP collection curated at the Museo Acatushún de Aves y Mamíferos Marinos Australes, Estancia Harberton, Tierra del Fuego, Argentina. All were collected in the period 1974 to 2011 during beach surveys carried out along the coast of northeastern Tierra del Fuego, from Cabo Espíritu Santo $\left(52^{\circ} 40^{\prime} \mathrm{S}\right.$, $\left.68^{\circ} 36^{\prime} \mathrm{W}\right)$ to Cabo San Pablo (54 $17^{\prime} \mathrm{S}, 6^{\circ} 45^{\prime} \mathrm{W}$ ) (Goodall 1978, Goodall \& Schiavini 1994, Goodall et al. 2008; Fig. 1). Most specimens were found in an advanced state of decomposition and had been partially eaten by scavengers or cut by fisherman, and the skulls, pelvic bones and pectoral fins were often missing or severely damaged. To standardize the data, we decided to limit our analyses to the complete postcranial axial skeleton. Data on the collec-

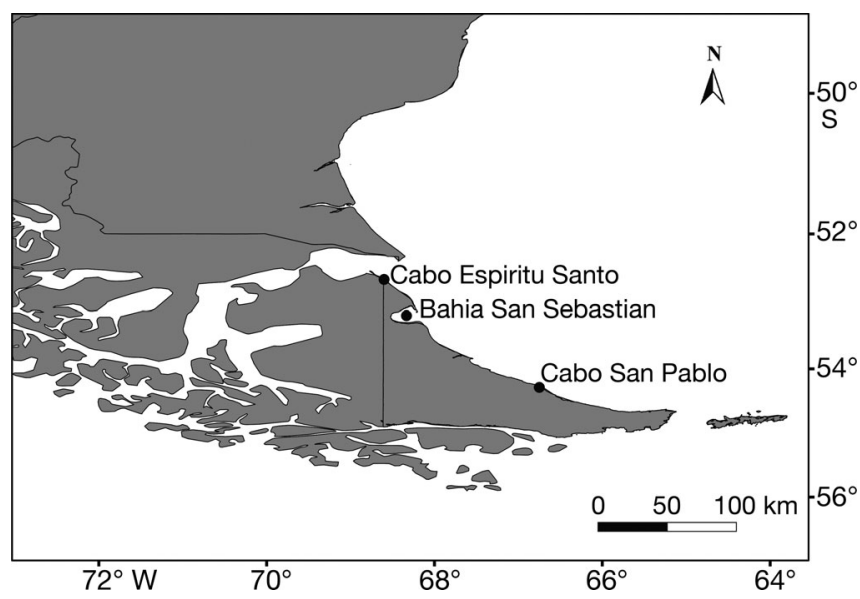

Fig. 1. Sites ( where most of the investigated Commerson's dolphins Cephalorhynchus c. commersonii were found stranded along the coast of Tierra del Fuego Island, Argentina 
tion date, stranding location, condition and type of skeleton (complete or incomplete) were available for all specimens. Sex was determined in 308 individuals, directly during necropsy or indirectly by examining the genital black patch of fresh specimens, by evaluating the form and size of the pelvic bones or by molecular testing using DNA amplified from teeth or bones (Pimper 2010, Pimper et al. 2010). Age was determined for 293 dolphins by counting the growth layer groups in dentin (Perrin \& Myrick 1980). Physical maturity, based on the status of epiphyseal fusion of vertebrae, was determined for 411 specimens, as follows: 0 -Fetus or newborn: unfused neural arch and vertebral discs; 1 -young dolphins, calves and juveniles under 5 yr old: fusion of the neural arch but not of the vertebral discs; 2-Subadult: fusions of some vertebral discs; 3 -Adult (physically mature): fusions of all vertebral discs (Perrin 1975, modified by Goodall et al. 1988). On the basis of the age and physical maturity, specimens were classified into an

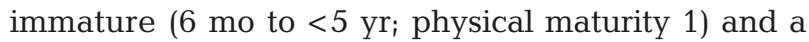
mature (from 5 yr onwards; physical maturity $2 \& 3$ ) category (Table 1).

\subsection{Identification of bone lesions}

All postcranial axial skeletons were macroscopically examined for the presence of pathologies and traumata. They were photographed, described and classified into 3 categories:

(1) Degenerative lesions. This category includes osteoarthritis, idiopathic hyperostosis of the spinal and transverse processes of the vertebrae and spondyloarthropathy.

(2) Traumatic lesions. This category includes healed and unhealed fractures.

(3) Spondylitis (spondylo-osteomyelitis) and spondylodiscitis. This condition is characterized by bone destruction (osteolysis), the development of cavities (cloacae) likely caused by the accumulation of pus, the formation of fistulae and new bone formation (Kompanje 1995b).

Table 1. Specimens of Commerson's dolphin (Cephalorhynchus c. commersonii) examined during the study

\begin{tabular}{|lcccc|}
\hline Age class & Males & Females & Unknown & Total \\
\hline Immature & 59 & 47 & 38 & 144 \\
Mature & 152 & 50 & 78 & 280 \\
Unknown & 0 & 0 & 1 & 1 \\
Total & 211 & 97 & 117 & 425 \\
\hline
\end{tabular}

\subsection{Data analysis}

To evaluate the significance of sexual variation and of the region of the vertebral column in the prevalence of idiopathic hyperostosis and spondyloarthropathy, we used a Pearson's Chi-squared Test for Count Data, in R (R v.1.1.456, RStudio: Integrated Development Environment for R). We evaluated the relationships between the occurrence of bone lesions and biological variables using generalized linear mixed-effects models. Mixed models accounted for the non-independence of data among repeated measures (in this case, different column regions from the same specimen; Pinheiro \& Bates 2000). We modeled only for idiopathic hyperostosis and spondyloarthropathy because the sample size for the other lesions was too small for statistical analysis.

The presence of vertebral pathologies was modeled as the response variable, while sex, age and the region of the vertebral column affected were modeled as fixed effects. The specimen identity (RNP number) was included in all the models as a random effect. For the analysis, we used only those specimens for which data on sex and age were available $(n=249)$. Five age categories were considered according to Lockyer et al. (1988): juvenile (6 mo to $2 \mathrm{yr})$, subadult (3-4 yr), early adult (58 yr), sexually adult (9-12 yr) and physically adult ( $>12$ yr). Models were constructed by backwards selection, removing non-significant fixed terms (as a function of the approximate p-values). For analyses, we used models with a binomial error distribution and a logit link function, with the maximum likelihood method of parameter estimation, with the specific packages nlme4 and lme4 in the statistical package R (R v.2.9.2; R Development Core Team 2008). The significance of the random effect was assessed using a maximum likelihood method (Pinheiro \& Bates 2000, Crawley 2007). Models were selected using Akaike's information criterion (AIC). The model with the lowest AIC value was taken to be the best approximating model, and subsequent models with an Akaike difference $<2$ were considered to also have substantial support from data (Burnham \& Anderson 2002).

\section{RESULTS}

The number of mature and immature individuals of each sex is provided in Table 1 . The postcranial axial skeletons of 107 (25.2\%) of 425 Commerson's dolphins Cephalorhynchus c. commersonii stranded 
along the coast of Tierra del Fuego in the period 1974 to 2011 had bone lesions or traumata. Among the 107 affected dolphins, idiopathic hyperostosis was the most frequent pathology $(73.8 \%)$, followed by spondyloarthropathy (40.2\%). Traumata (25.2\%), spondylitis and spondylodiscitis (10.3\%) and osteoarthritis (11.2\%) occurred less frequently (Fig. 2).

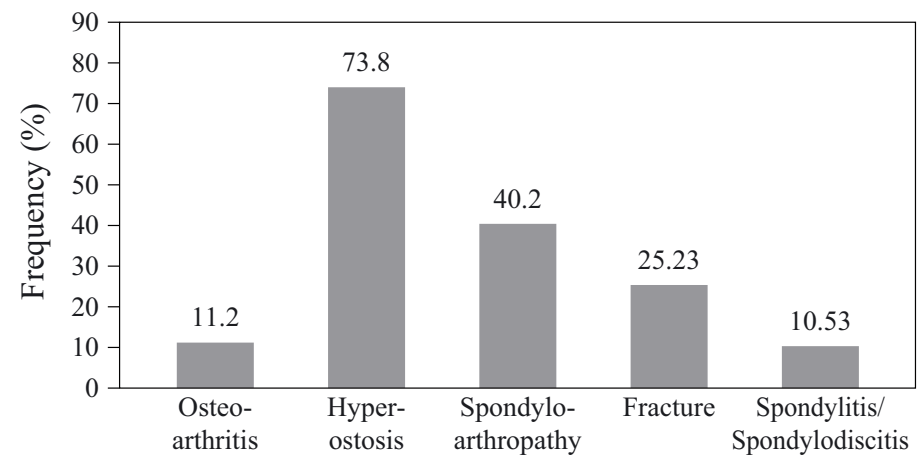

Fig. 2. Frequency of occurrence (\%) of bone pathologies among 107 affected Commerson's dolphins Cephalorhynchus c. commersonii (of 425 ind. surveyed) from Tierra del Fuego, Argentina

\subsection{Degenerative lesions}

\subsubsection{Osteoarthritis}

Osteoarthritis affected the transverse processes of the thoracic vertebrae of 6 males, 3 females and 3 individuals of undetermined sex, all physically mature and 9 of them (6 males and 3 females) aged between 6 and 16 yr (Fig. 3a). The prevalence of this condition was $2.82 \%$ in the 425 C. c. commersonii.

\subsubsection{Idiopathic hyperostosis}

Idiopathic hyperostosis was detected in 79 mature specimens, including 52 males, 9 females and 18 dolphins of undetermined sex. This condition was characterized by bone overgrowth at the surface of the spinal and transverse processes (Fig. 3b). The prevalence was $18.6 \%$ in the 425 specimens. It was significantly $\left(\chi_{1}^{2}=9.879, \mathrm{p}=0.001672\right)$ higher in males $(24.6 \%, \mathrm{n}=211)$ than in females $(9.2 \%, \mathrm{n}=97)$. The lumbar vertebrae were significantly $\left(\chi^{2}{ }_{3}=132.08, \mathrm{p}<\right.$

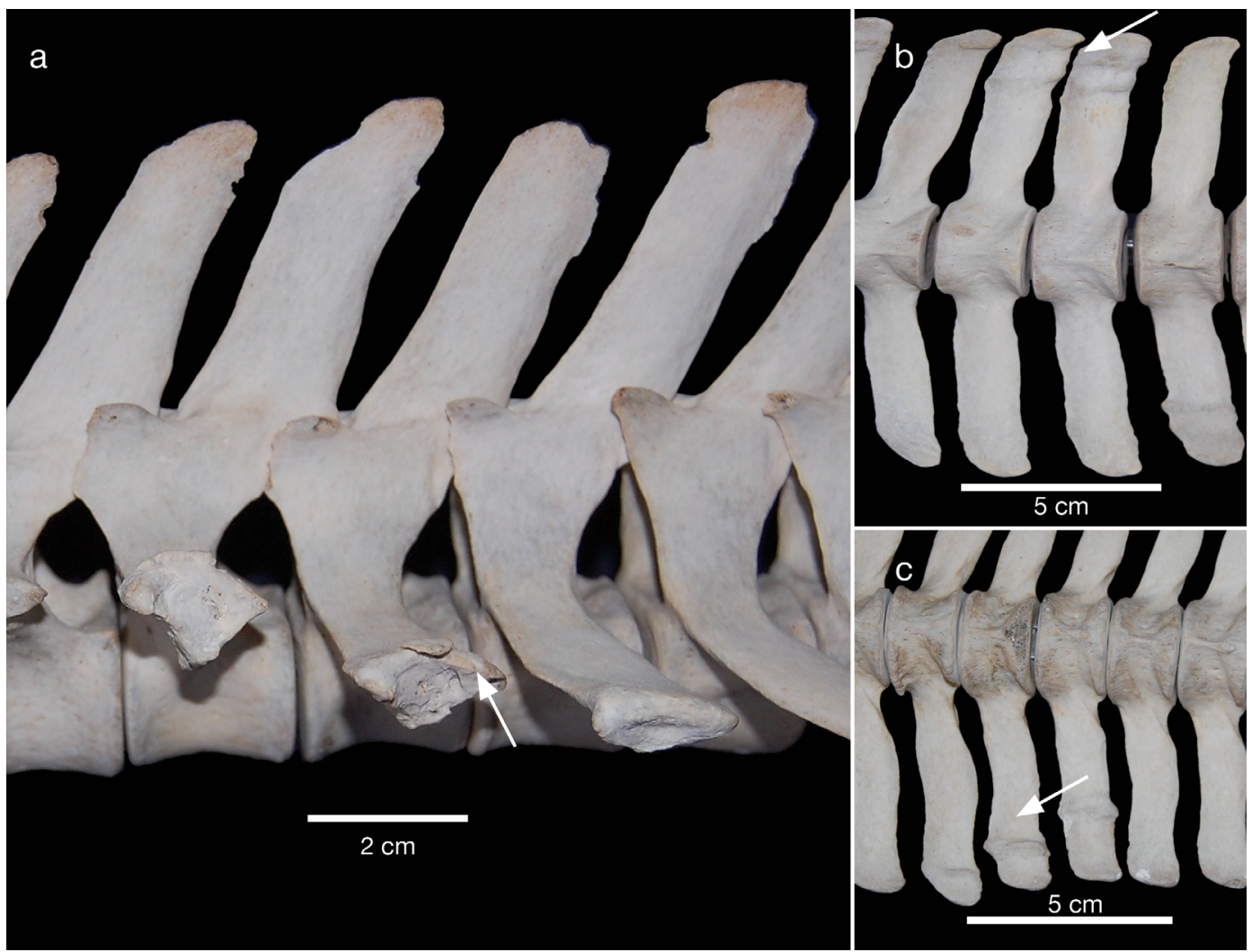

Fig. 3. (a) Osteoarthritis in the thoracic vertebra of a Commerson's dolphin Cephalorhynchus c. commersonii RNP 2310, as evidenced by bone overgrowth (arrow) on the extremity of the transverse processes; (b) and (c) idiopathic hyperostosis on the transverse process of lumbar vertebrae (ventral view) of RNP 2244 and RNP 2336 (the arrows indicate the overgrowth) 
$0.0001)$ more frequently $(77.2 \%, \mathrm{n}=61)$ affected than the other parts of the vertebral column, followed by the thoracic vertebrae $(48.1 \%, \mathrm{n}=38)$.

\subsubsection{Spondyloarthropathy}

Spondyloarthropathy was detected in 43 (10.11\%) of the 425 C. c. commersonii, including 3 immature and 40 mature specimens. Eight of them had severe ankylosis of $\geq 2$ cervical and/or thoracic vertebrae (Table 2, Fig. 4).

No significant $\left(\chi_{1}^{2}=0.057987, p=0.8097\right)$ differences in prevalence were found between males $(10.4 \%, \mathrm{n}=211)$ and females $(11.34 \%, \mathrm{n}=97)$, and sexes were grouped for subsequent analysis. The disease occurred significantly $\left(\chi_{1}^{2}=15.538, \mathrm{p}<0.0001\right)$ more frequently in mature $(14.3 \%, \mathrm{n}=40)$ than in immature $(2.08 \%, \mathrm{n}=3)$ specimens. Though it af- fected all regions of the vertebral column, it occurred significantly $\left(\chi_{3}^{2}=31.702, p<0.0001\right)$ more frequently in the thoracic $(88.4 \%, \mathrm{n}=38)$ and caudal $(69.8 \%, \mathrm{n}=30)$ vertebrae than in the cervical $(34.9 \%$, $\mathrm{n}=15)$ and lumbar regions $(44.2 \%, \mathrm{n}=19)$ in the 43 affected dolphins.

\subsubsection{Traumata}

A total of 27 specimens, most of them (89\%) adults, had different types of fractures (Fig. 5). Among males, 9 had fractures of the ribs, 1 had an unhealed fracture of the transverse process of the thoracic vertebra, and 2 had healed and unhealed fractures of the transverse process of a lumbar vertebra. The 8 positive females and 7 specimens of undetermined sex had fractures of the ribs. Global fracture prevalence was $6.35 \%$ in the 425 Commerson's dolphins.

Table 2. Spondyloarthropathy with ankylosis in Commerson's dolphin Cephalorhynchus c. commersonii from Tierra del Fuego, Argentina. Specimen numbers refer to the R. Natalie P. Goodall collection

\begin{tabular}{|c|c|c|c|c|c|}
\hline Specimen & Sex & $\begin{array}{l}\text { Age } \\
(\mathrm{yr})\end{array}$ & $\begin{array}{l}\text { Age } \\
\text { class }\end{array}$ & Date found & Description \\
\hline 1054 & M & 4 & 2 & 18 Jan 1983 & Fusions of 2 lumbar (L9-10) vertebrae \\
\hline 1858 & M & 11 & 3 & 25 Feb 1995 & Fusion of all cervical vertebrae \\
\hline 1872 & $\mathrm{U}$ & $\mathrm{U}$ & 2 & 25 Feb 1995 & Fusion of 6 thoracic (Th6-11) vertebrae \\
\hline 1924 & $\mathrm{~F}$ & 6 & 2 & 19 Apr 1995 & Fusion of 2 cervical (Cv6-7) vertebrae \\
\hline 1991 & $\mathrm{U}$ & $\mathrm{U}$ & 3 & 22 Feb 1997 & $\begin{array}{l}\text { Fusion of } 2 \text { thoracic (Th5-6) vertebrae; formation of marginal osteo- } \\
\text { phytes in all thoracic vertebrae }\end{array}$ \\
\hline 2173 & $\mathrm{~F}$ & 6 & 3 & 14 Nov 2000 & $\begin{array}{l}\text { Fusion of } 3(\mathrm{Cv} 3-5) \text { cervical and } 3 \text { thoracic }(\mathrm{Th} 6-8) \text { vertebrae; } \\
\text { formation of osteophytes in all cervical and thoracic vertebrae }\end{array}$ \\
\hline 2245 & $\mathrm{M}$ & $\mathrm{U}$ & 3 & 10 Mar 2002 & Partial fusion of 2 cervical vertebrae (Cv4-5) \\
\hline 2268 & $\mathrm{~F}$ & 13 & 3 & 06 Jan 2003 & $\begin{array}{l}\text { Fusion of } 2(\mathrm{Cv} 3-4) \text { cervical vertebrae; osteophytes on the ventral } \\
\text { side of at least another cervical vertebra }\end{array}$ \\
\hline
\end{tabular}
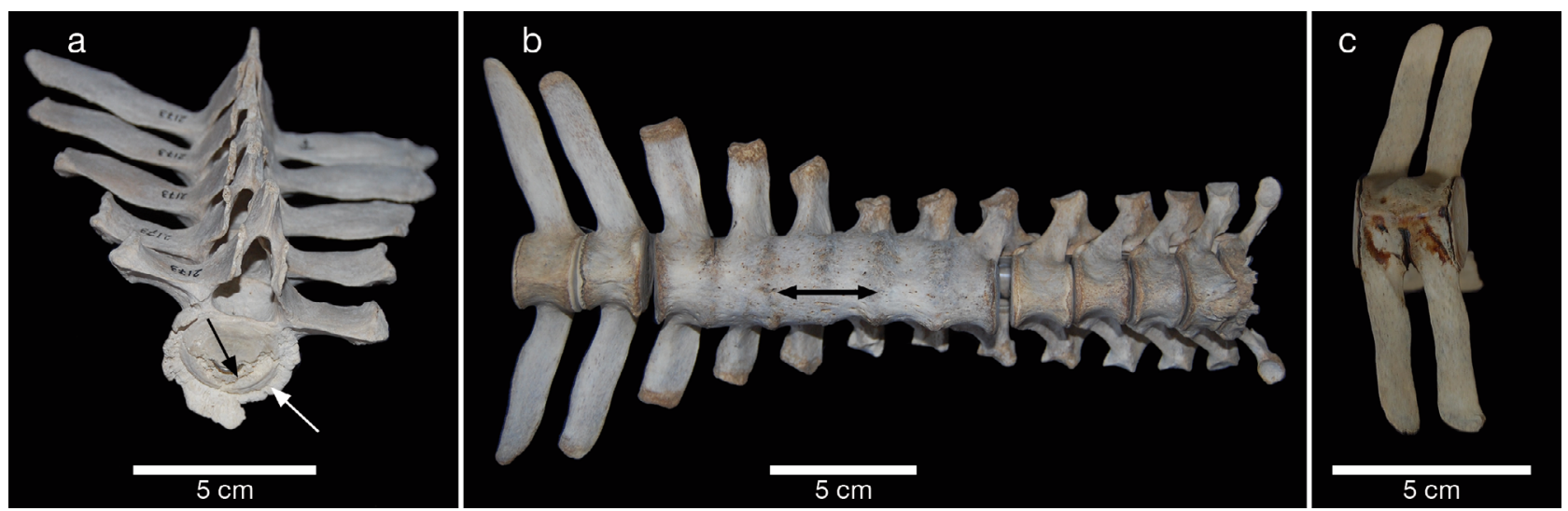

Fig. 4. Spondyloarthropathy in Commerson's dolphins Cephalorhynchus C. commersonii): (a) thoracic vertebral body (Th1) with disc erosion (black arrow) and marginal osteophytes (white arrow) in mature female (RNP 2173); (b) overgrowth of the osteophytes in contiguous vertebrae and ventral ankylosis of the thoracic vertebrae 6-11 (double arrow,) in mature specimen (RNP 1872) and (c) 2 lumbar (L9-10) vertebrae with ventral ankylosis in mature male (RNP 1054) 


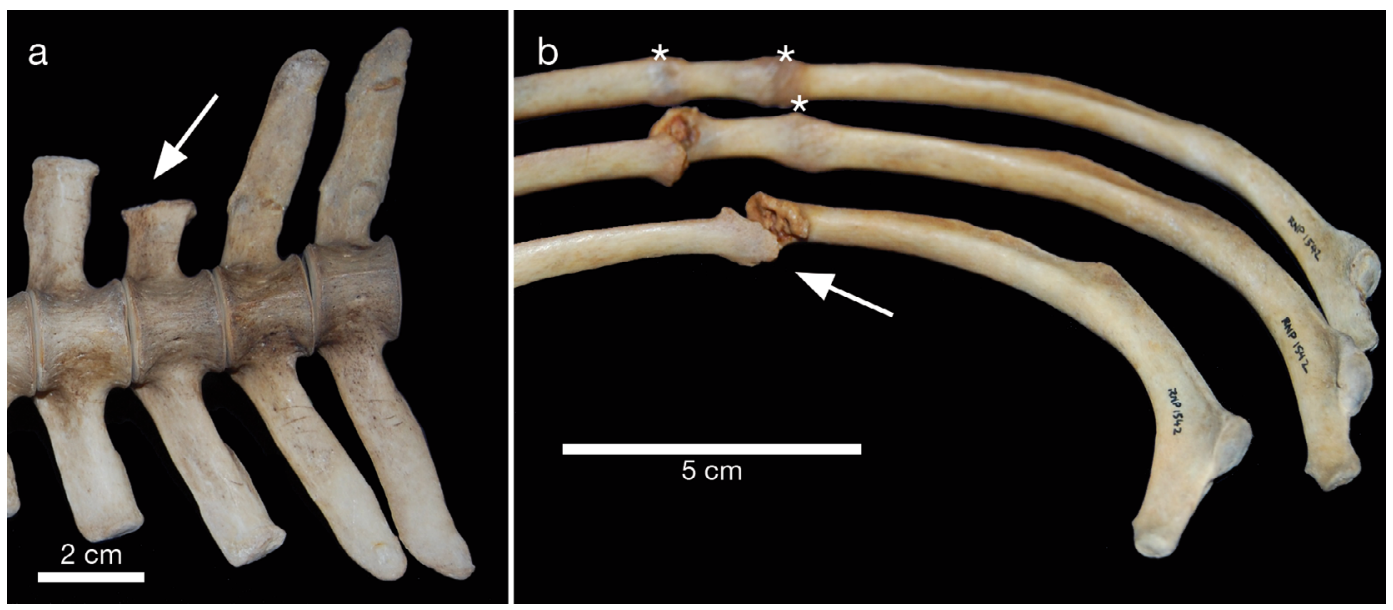

Fig. 5. Fractures in Commerson's dolphins Cephalorhynchus c. commersonii: (a) complete fracture (arrow) of the transverse process of the tenth thoracic vertebra in a male mature RNP 2708; (b) healed (asterisk) and unhealed fractures of the ribs of male mature RNP 1542

\subsubsection{Spondylitis and spondylodiscitis}

Spondylitis and spondylodiscitis were detected in the cervical, thoracic, lumbar and caudal regions of 11 individuals (Fig. 6), 6 of them immature. Prevalence of these conditions was $2.6 \%$ in the 425 specimens. The lesions were limited to 1 or 2 vertebrae in 5 dolphins. In 4 others, they were more severe, with large areas of bone destruction and new bone formation affecting 2 to 10 vertebrae (Fig. 6a,b). In another individual, an immature male (RNP 1338), $>50 \%$ of the vertebrae were affected. Localized osteolysis and cloacae were seen in 5 thoracic vertebrae $(6-8$ and 10-11). Bone destruction and new bone formation were observed in all lumbar vertebrae and in most of the caudal vertebrae. Finally, in a mature female (RNP 1875) osteolysis and new formation were observed on the transverse processes of 3 lumbar vertebrae.

\subsubsection{Undetermined}

Extensive bone remodeling and limited osteolysis were observed on 4 caudal vertebrae of a $4 \mathrm{yr}$ old immature female (Fig. 7). Though these lesions may have been related to osteomyelitis, they may also have had a metabolic etiology.

\subsection{Statistics and model analysis}

The best-supported model to explain the occurrence of idiopathic hyperostosis included the region of the vertebral column as the only explanatory vari- able. This model indicated that the prevalence of idiopathic hyperostosis is higher in the thoracic and lumbar vertebrae than in those in the caudal and cervical regions (Table 3). The variability explained by the random effect was significant in the final model $(\mathrm{p} \leq 0.001)$.

Similar results were observed for spondyloarthropathy, with the region of the vertebral column being the only significant explanatory variable in the model with the lowest AIC score. This model suggested that the probability of having spondyloarthropathy is lower in the lumbar region than in the other regions (Table 4). The variability explained by the identity (ID number) of the specimens was significant in the final model $(p \leq 0.001)$. Sex and age did not significantly affect the occurrence of this condition.

\section{DISCUSSION}

During this study, we observed spondylitis and spondylodiscitis, degenerative lesions and traumata in the postcranial axial skeletal of 107 Commerson's dolphins Cephalorhynchus c. commersonii stranded or by-caught along the coast of Tierra del Fuego in the period 1974 to 2011, with a global prevalence of $25.2 \%(\mathrm{n}=425)$. In comparison, the prevalence of postcranial axial skeletal pathologies was $41 \%$ in 78 sympatric Peale's dolphins Lagenorhynchus australis (San Martín et al. 2016). The large number $(\mathrm{n}=249)$ of Commerson's dolphin specimens for which the age was determined allowed the use of generalized linear mixed-effects models to explore the relation between prevalence and biological variables, such as 

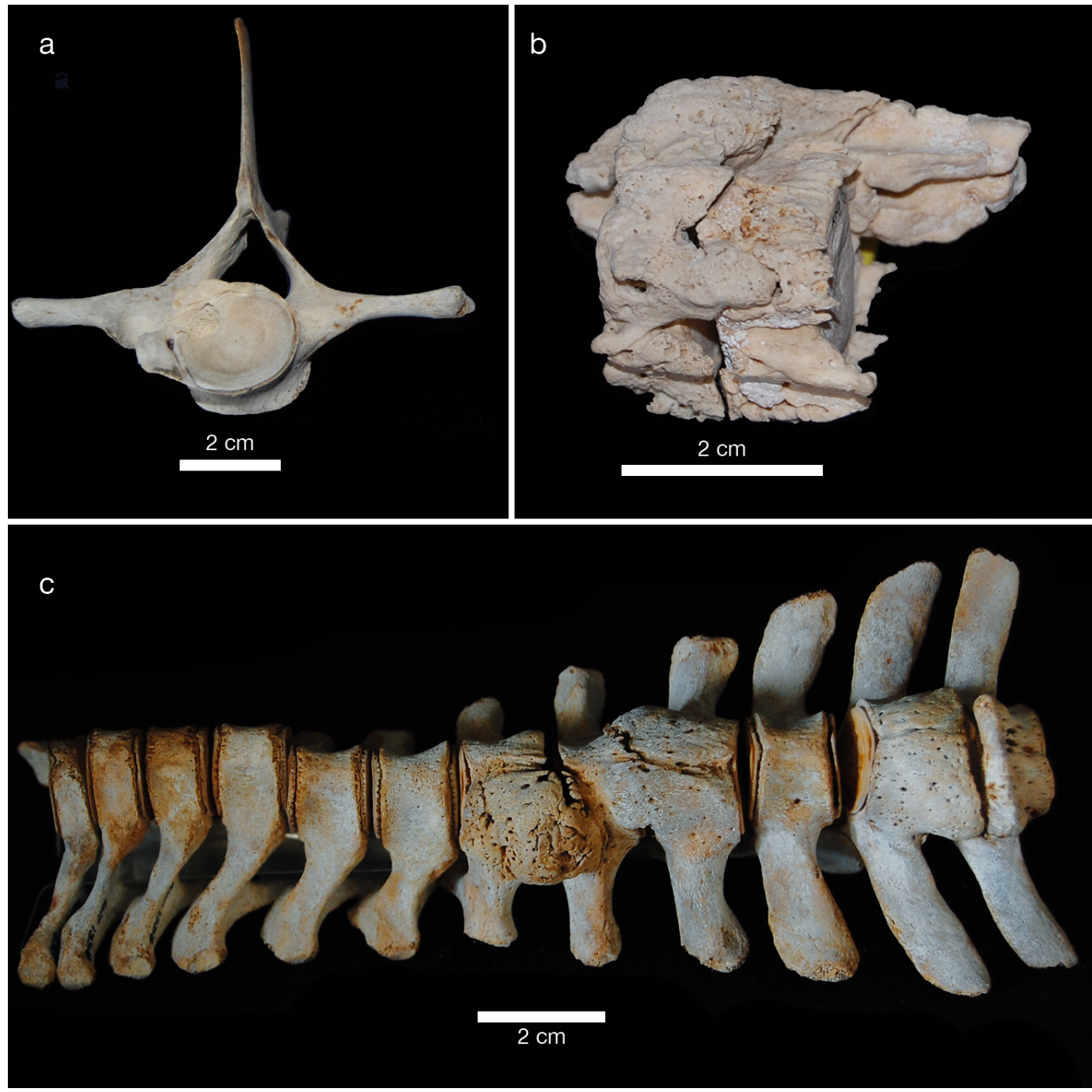

Fig. 6. (a) Osteolysis in an intervertebral disc and new bone formation in the thoracic vertebrae of immature male RNP 1691 (spondylodiscitis); (b) lysis and bone remodeling in several caudal vertebrae of mature female RNP 2254 (spondylodiscitis); (c) osteomyelitis in 5 thoracic vertebrae (spondylitis) of immature male RNP 1338
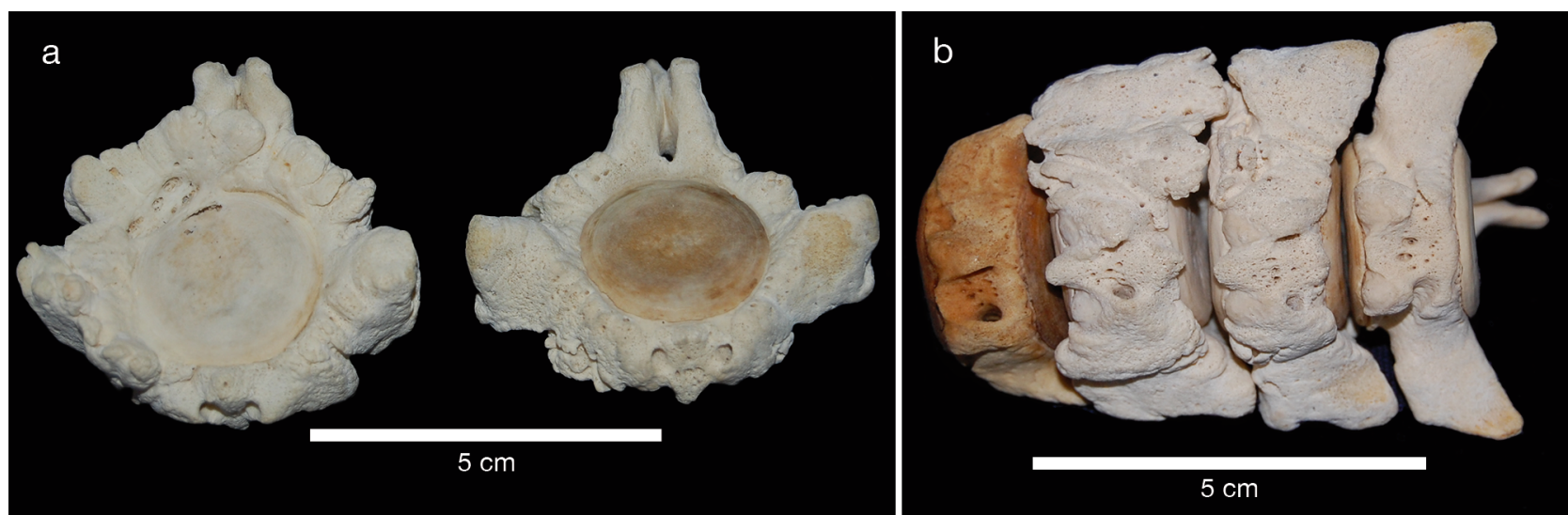

Fig. 7. Undetermined bone disease in immature female Commerson's dolphin RNP-1894: (a) new bone formation and presence of cloaca in caudal vertebrae ( $\mathrm{Ca}$ 9) (b) bone destruction and new bone formation in 4 caudal vertebrae (Ca 8-11) 
Table 3. Final model for the presence of idiopathic hyperostosis. The identity (RNP number) of the animal was included as a random effect. SE: standard error. Significant p-values in bold

\begin{tabular}{|lcc|}
\hline Fixed effect & Coefficient $( \pm 1 \mathrm{SE})$ & $\mathrm{p}$ \\
\hline Intercept & $14.0( \pm 2.21)$ & $<<\mathbf{0 . 0 0 1}$ \\
Cervical region & $0.75( \pm 1.31)$ & 0.57 \\
Thoracic region & $4.39( \pm 1.43)$ & $\mathbf{0 . 0 0 2}$ \\
Lumbar region & $5.52( \pm 1.48)$ & $\mathbf{0 . 0 0 0 2}$ \\
\hline
\end{tabular}

Table 4. Final model for the presence of spondyloarthropathy. The identity (RNP number) of the animal was included as a random effect. SE: standard error. Significant p-values in bold

\begin{tabular}{|lrl|}
\hline Fixed effect & Coefficient $( \pm 1 \mathrm{SE})$ & $\mathrm{p}$ \\
\hline Intercept & $-14.84( \pm 20.9)$ & 0.477 \\
Age & $0.80( \pm 4.25)$ & 0.84 \\
Cervical region & $-1.78( \pm 1.10)$ & 0.10 \\
Thoracic region & $0.59( \pm 1.19)$ & 0.65 \\
Lumbar region & $-2.99( \pm 1.32)$ & $\mathbf{0 . 0 1 2}$ \\
Sex & $2.22( \pm 8.60)$ & 0.79 \\
\hline
\end{tabular}

sex, age classes and regions of the vertebral column. The best-supported model to explain the occurrence of idiopathic hyperostosis and spondyloarthropathy in these specimens included the region of the vertebral column as the only explanatory variable, with a higher probability of idiopathic hyperostosis in the thoracic and lumbar vertebrae than in the cervical and caudal ones but a lower probability of spondyloarthropathy in the lumbar region than in the other ones.

Idiopathic hyperostosis was the lesion most frequently observed in Commerson's dolphins, mostly affecting adults and often occurring in the thoracic and lumbar vertebrae. Similarly, San Martín et al. (2016) found idiopathic hyperostosis in the thoracic vertebrae of $25 \%$ of the 78 Peale's dolphins examined. There are only a few papers on the occurrence of this pathology in the axial skeleton of cetaceans (Van Bressem et al. 2007, San Martín et al. 2016). In offshore common bottlenose dolphins Tursiops truncatus from Peru, idiopathic hyperostosis seemed to be linked to the development of ankylosing spondylitis (Van Bressem et al. 2007), a form of spondyloarthropathy (Kompanje 1999).

Spondyloarthropathy was the second most commonly detected pathology in Commerson's dolphins, affecting the whole vertebral column, though with a higher occurrence in the thoracic and caudal regions. Similarly, this condition mostly affected the thoracic vertebrae of Peale's dolphins from the same ocean province (San Martín et al. 2016). The typical behavior of these species, including high-speed swimming and abrupt changes in direction that require high maneuverability and, likely, a greater mobility of the cervical-thoracic region (Goodall \& Schiavini 1994, Marchesi et al. 2017), may be at the origin of this pathology. Spondyloarthropathy has also been described in the humpback whale Megaptera novaeangliae (Hellier et al. 2011), fin whale Baleanoptera physalus and the white-beaked Lagenorhynchus albirostris (Kompanje 1999) among other species. Factors such as a bulky body, elevated vertebrae number and age are suspected to play a role in its etiology (Kompanje 1993, Galatius et al. 2009). Related to intervertebral cartilage wear, bone overgrowth worsens with age and occurs more frequently in older specimens (Kompanje 1993).

Osteoarthritis mostly affected the thoracic vertebrae in adult males and females. Several factors have been implicated in the pathogenesis of this degenerative disease, including increasing age, excessive joint stress and decreased joint lubrication (McKeag 1992, Lane \& Buckwalter 1993, O'Connor \& Brandt 1993). However, as cetaceans live in a weight-supporting medium and do not bear excessive weight on their joints, joint stress likely did not play a major role in the development of this condition (Turnbull \& Cowan 1999). As osteoarthritis was only reported in mature individuals, it is possible that age also represents a risk factor in the development of this pathology in the Commerson's dolphin.

The healed and unhealed fractures of the ribs observed in 27 dolphins may have been the results of ship strikes and of inter- and intraspecific interactions (Duignan et al. 2003, Van Bressem et al. 2007, Van Waerebeek et al. 2007). Commerson's dolphins are often observed close to ferries or bow riding in the Magellan Strait (Goodall et al. 1988). They also regularly interact with Peale's dolphins and southern sea lions Otaria flavenscens, though aggressions have not been reported (Goodall et al. 1988). Aggressive interactions between bottlenose dolphins and Commerson's dolphins were described in Bahía Engaño, Patagonia, Argentina, in November 2001, but seem infrequent (Coscarella \& Crespo 2010).

During this study, we observed spondylitis and spondylodiscitis in 11 specimens. The lesions often occurred in the caudal region and were in some cases accompanied by ankylosis. They affected 1, 2 or more vertebrae. Deformation, lysis of the intervertebral discs and osteolysis of the vertebrae were observed in all cases. The origin of these lesions is unknown, but bacteria, such as Brucella spp., might be the culprit 
(Kompanje 1996, Sweeny et al. 2005, Félix et al. 2007, Goertz et al. 2011). Unfortunately, the cleaning process of the skeletons for the Museum collection prevented any attempt to isolate the etiologic agent(s).

Together these data indicate that bone lesions and traumata commonly occur in Commerson's dolphins, likely causing severe pain and morbidity in severe cases, as described in humans and other mammals (Ragetly 2008, Lascelles 2010, van Weeren \& Grauw 2010). This paper provides the first insight into the bone pathologies of Commerson's dolphins from Argentina and contributes to baseline data on the biology of and threats affecting this species. It also lays the basis for comparative studies with other coastal and oceanic cetacean species from the Southwest Atlantic Ocean and other ocean provinces.

Acknowledgements. We kindly acknowledge Dr. Koen Van Waerebeek and 2 anonymous reviewers for their constructive comments on the manuscript. We thank the 'Fundación R. Natalie P. Goodall-Museo Acatushún de Aves y Mamíferos Marinos Australes' for allowing us to access the RNP collection. A.A.S.M., N.A.D. and E.J.G. are members of the Consejo Nacional de Investigaciones Científicas y Técnicas (CONICET) of Argentina, which is also funding the doctoral thesis of A.A.S.M. We thank the Cetacean Society International for funding this project.

\section{LITERATURE CITED}

Bertulli CG, Galatius A, Kinze CC, Rasmussen MH and others (2015) Vertebral column deformities in white-beaked dolphins from the eastern North Atlantic. Dis Aquat Org 116:59-67

Burnham KP, Anderson DR (2002) Model selection and multimodel inference: a practical information-theoretic approach. Springer-Verlag, New York, NY

Coscarella MA, Crespo EA (2010) Feeding aggregation and aggressive interaction between bottlenose (Tursiops truncatus) and Commerson's dolphins (Cephalorhynchus commersonii) in Patagonia, Argentina. J Ethol 28:183-187

Crawley MJ (2007) The R book. John Wiley \& Sons, West Sussex

de Smet WMA (1977) The fate of old bottlenose dolphins, Tursiops truncatus, in nature, as revealed by the condition of their skeletons. Aquat Mamm 5:78-86

Duignan PJ, Gibbs NJ, Jones GW (2003) Autopsy of cetaceans incidentally caught in fishing operations 1997/98, 1999/2000, and 2000/01. DOC Science Internal Series 119. Department of Conservation, Wellington

Félix F, Haase B, Aguirre WE (2007) Spondylitis in a humpback whale (Megaptera novaeangliae) from the southeast Pacific. Dis Aquat Org 75:259-264

Galatius A, Sonne C, Kinze CC, Dietz R, Jensen JEB (2009) Occurrence of vertebral osteophytosis in a museum sample of white-beaked dolphins (Lagenorhynchus albirostris) from Danish waters. J Wildl Dis 45:19-28

Goertz CE, Frasca S Jr, Bohach GA, Cowan DF and others (2011) Brucella sp. vertebral osteomyelitis with intercurrent fatal Staphylococcus aureus toxigenic enteritis in a bottlenose dolphin (Tursiops truncatus). J Vet Diagn Invest 23:845-851

Goodall RNP (1978) Report on the small cetacean stranded on the coasts of Tierra del Fuego. Rep Int Whaling Comm 30:197-230

Goodall RNP, Galeazzi AR, Leatherwood S, Miller KW, Cameron IS, Kastelein RK, Sobral AP (1988) Studies of Commerson's dolphin, Cephalorhynchus commersonii, of Tierra del Fuego, 1976-1984, with a review of information on the species in the South Atlantic. Rep Int Whal Comm Spec Issue 9:3-70

Goodall RNP, Schiavini ACM (1994) Net fisheries and net mortality of small cetaceans of Tierra del Fuego, Argentina. Rep Int Whal Spec Issue 15:295-306

Goodall RNP, Dellabianca N, Boy CC, Benegas LG, Pimper LE, Riccialdelli L (2008) Review of small cetaceans stranded or incidentally captured on the coasts of Tierra del Fuego, Argentina, over 33 years. Sci Comm Doc SC/ 60/SM21. International Whaling Commission, Cambridge

Groch KR, Marcondes MCC, Colosio AC, Catão-Dias JL (2012) Skeletal abnormalities in humpback whales Megaptera novaeangliae stranded in the Brazilian breeding ground. Dis Aquat Org 101:145-158

Hellier CA, Hufthammer AK, Lislevand T (2011) Osteological pathology in a humpback (Megaptera novaeangliae) and fin (Balaenoptera physalus) whale skeleton. Int J Paleopathol 1:117-120

* Iñíguez MA, Hevia M, Gasparrou C, Tomsin AL, Secchi ER (2003) Preliminary estimate of incidental mortality of Commerson's dolphins (Cephalorhynchus commersonii) in an artisanal setnet fishery in la Angelina beach and Ría gallegos, Santa Cruz, Argentina. Lat Am J Aquat Mamm 2:87-94

Kompanje EJO (1993) Vertebral osteophytosis in cetacean spondylosis or spondylitis? Z Saugetierkd 58:316-318

Kompanje EJO (1995a) On the occurrence of spondylosis deformans in white-beaked dolphins Lagenorhynchus albirostris (Gray, 1846) stranded on the Dutch coast. Zool Meded 69:231-250

Kompanje EJO (1995b) Differences between spondyloosteomyelitis and spondylosis deformans in small odontocetes based on museum material. Aquat Mamm 21: 199-203

Kompanje EJO (1996) Intervertebral disc degeneration and discarthrosis in white-beaked dolphins (Lagenorhynchus albirostris). Annual meeting EAZWV Rostock, p 21-25

Kompanje EJO (1999) Considerations on the comparative pathology of the vertebrae in Mysticeti and Odontoceti; evidence for the occurrence of discarthrosis, zygarthrosis, infectious spondylitis and spondyloarthritis. Zool Meded 73:99-130

Kompanje EJO, García Hartmann MA (2001) Intraspongious disc herniation (Schmorl's node) in Phocoena phocoena and Lagenorhynchus albirostris (Mammalia: Cetacea, Odontoceti). Deinsea 8:135-141

La Sala LF, Pozzi LM, McAloose D, Kaplan FS and others (2012) Severe soft tissue ossification in a southern right whale Eubalaena australis. Dis Aquat Org 102: 149-156

* Laeta M, Souza SMF, Siciliano S (2010) Anomalías ósseas congênitas em Sotalia guianensis (Mammalia, Cetacea, Delphinidae) da costa centro-norte do estado do Rio de Janeiro. Pesqui Vet Bras 30:484-490

Lagier R (1989) Spinal hyperostosis in comparative pathology. Skeletal Radiol 18:99-107 
Lane NE, Buckwalter JA (1993) Exercise: a cause of osteoarthritis? Rheum Dis Clin North Am 19:617-633

Lascelles BDX (2010) Feline degenerative joint disease. Vet Surg 39:2-13

Lockyer C, Goodall RNP, Galeazzi AR (1988) Age and body length characteristics of Cephalorhynchus commersonii from incidentally-caught specimens off Tierra del Fuego. Rep Int Whaling Comm 9:103-118

Marchesi MC, Mora MS, Pimper LE, Crespo EA, Goodall RNP (2017) Can habitat characteristics shape vertebral morphology in dolphins? An example of two phylogenetically related species from southern South America. Mar Mamm Sci 33:1126-1148

Martel-Pelletier J (2004) Pathophysiology of osteoarthritis. Osteoarthritis Cartilage 12:31-33

McKeag DB (1992) The relationship of osteoarthritis and exercise. Clin Sports Med 11:471-487

Nganvongpanit K, Soponteerakul R, Kaewkumpai P, Punyapornwithaya $V$, Buddhachat $K$, Nomsiri $R$ and others (2017) Osteoarthritis in two marine mammals and 22 land mammals: learning from skeletal remains. J Anat 231: 140-155

O'Connor BL, Brandt KD (1993) Neurogenic factors in the etiopathogenesis of osteoarthritis. Rheum Dis Clin North Am 19:581-605

Oremland MS, Bernadette MA, Clapham PJ, Moore MJ, Potter C, Mead JG (2010) Mandibular fractures in shortfinned pilot whales, Globicephala macrorhynchus. Mar Mamm Sci 26:1-16

Perrin WF (1975) Variation of spotted and spinner porpoises (genus Stenella) in the eastern tropical Pacific and Hawaii. Bull Scripps Inst Oceanogr Univ Calif 21:1-205

Perrin WF, Myrick AC (eds) (1980) Age determination of toothed whales and sirenians. Rep Int Whal Comm Spec Issue 3. IWC, Cambridge

Pimper LE (2010) Estructura poblacional y conservación de la tonina overa, Cephalorhynchus commersonii, en Tierra de Fuego y zonas aledañas. PhD dissertation, Universidad de Buenos Aires

Pimper LE, Baker CS, Goodall RNP, Olivarría C, Remis MI (2010) Mitochondrial DNA varation and population structure of Commerson's dolphins (Cephalorhynchus

Editorial responsibility: Michael Moore, Woods Hole, Massachusetts, USA commersonii) in their southernmost distribution. Conserv Genet 11:2157-2168

Pinheiro JC, Bates DM (2000) Mixed-effects models in S and S-plus. Springer, Berlin, Heidelberg, New York, NY

R Development Core Team (2008) R: a language and environment for statistical computing. R Foundation for Statistical Computing, Vienna. www.r-project.org

Ragetly G (2008) Spondylodiscitis in dogs and cats. Point Vét 39:31-34

* Robineau DP, Goodall RN, Pichler F, Baker CS (2007) Description of a new subspecies of Commerson's dolphin, Cephalorhynchus Commersonii (Lacépède, 1804), inhabiting the coastal waters of the Kerguelen Islands. Mammalia 71:172-180

Salter DM (2002) Degenerative joint diseases. Curr Diagn Pathol 8:11-18

* San Martín AA, Macnie SV, Goodall RNP, Boy CC (2016) Pathology in skeletons of Peale's dolphin Lagenorhynchus australis from southern South America. Dis Aquat Org 120:9-15

* Sweeny MM, Price JM, Jones GS, French TW, Early GA, Moore MJ (2005) Spondylitic changes in long-finned pilot whales (Globicephala melas) stranded on Cape Cod, Massachusetts, USA, between 1982 and 2000. J Wildl Dis 41:717-727

Turnbull BS, Cowan DF (1999) Synovial joint disease in wild cetaceans. J Wildl Dis 35:511-518

*Van Bressem MF, Van Waerebeek K, Montes D, Kennedy S and others (2006) Diseases, lesions and malformations in the long-beaked common dolphin Delphinus capensis from the Southeast Pacific. Dis Aquat Org 68:149-165

*Van Bressem MF, Van Waerebeek K, Reyes JC, Félix F, Echegaray $M$ and others (2007) A preliminary overview of skin and skeletal diseases and traumata in small cetaceans from South American waters. Lat Am J Aquat Mamm 6:7-42

Van Waerebeek K, Baker AN, Felix F, Gedamke J and others (2007) Vessel collisions with small cetaceans worldwide and with large whales in the Southern Hemisphere, an initial assessment. Lat Am J Aquat Mamm 6:43-69

van Weeren PR, de Grauw JC (2010) Pain in osteoarthritis. Vet Clin North Am Equine Pract 26:619-642

Submitted: March 7, 2019; Accepted: July 19, 2019

Proofs received from author(s): September 18, 2019 